\title{
Determinantes do nível de disclosure de instrumentos financeiros derivativos em firmas brasileiras
}

\section{Determinants of disclosure level of derivative financial instruments by brazilian public companies}

\author{
Patrícia Vasconcelos Rocha Mapurunga \\ Mestranda em Administração e Controladoria da Faculdade de Economia, Administração, Atuária, Contabilidade e Secretariado da \\ Universidade Federal do Ceará \\ E-mail: pattivasconcelos@hotmail.com \\ Vera Maria Rodrigues Ponte \\ Professora Doutora do Departamento de Contabilidade da Faculdade de Economia, Administração, Atuária e Contabilidade da Universidade \\ Federal do Ceará \\ E-mail: vponte@fortalnet.com.br \\ Antônio Carlos Dias Coelho \\ Professor Associado-Pós-Doutor do Programa de Pós-Graduação em Administração e Controladoria da Faculdade de Economia, Administração, \\ Atuária e Contabilidade da Universidade Federal do Ceará \\ E-mail: acarloscoelho@terra.com.br
}

Anelise Florencio de Meneses

Mestranda em Administração e Controladoria da Faculdade de Economia, Administração, Atuária, Contabilidade e Secretariado da Universidade Federal do Ceará

E-mail: anelisefm@gmail.com

Recebido em 30.03.2011 - Aceito em 16.06.2011 - $2^{a}$. versão aceita em 24.08.2011

\section{RESUMO}

A pesquisa teve por objetivo verificar a existência de associação entre a divulgação de informações acerca de instrumentos financeiros derivativos e características econômicas de sociedades brasileiras de Capital Aberto. Para tanto, realizou-se levantamento em demonstrações financeiras padronizadas de $75 \mathrm{com}$ panhias listadas nos Níveis Diferenciados de Governança Corporativa da BM\&FBovespa. Na primeira etapa, pesquisa documental identificou as informações acerca dos instrumentos financeiros derivativos divulgados pelas empresas, adotando-se métrica desenvolvida a partir dos dispositivos constantes do Pronunciamento Técnico CPC 14 - Instrumentos Financeiros: Reconhecimento, Mensuração e Evidenciação. Em análise preliminar, verificou-se que nenhuma das empresas da amostra apresentou todos os itens de evidenciação requeridos, bem como que apenas 11 , dos 30 itens de evidenciação, foram divulgados por mais de $50 \%$ das companhias constantes da amostra. Em seguida, procedeu-se à Análise de Correspondência (ANACOR) para verificar a associação entre os atributos das firmas e seu nível de evidenciação. No que tange aos resultados obtidos, verificou-se que os atributos 'Tamanho' e 'Lucro' estão, positivamente, associados à divulgação de informações sobre instrumentos financeiros derivativos, não se verificando associação significante entre os atributos 'Endividamento' e 'Rentabilidade', com a divulgação de informações sobre instrumentos financeiros derivativos.

Palavras-chave: Evidenciação. Instrumentos financeiros derivativos. Análise de correspondência. 


\section{ABSTRACT}

The purpose of this study was to verify the existence of an association between disclosure of information on derivative financial instruments and the economic attributes of Brazilian public companies. Data were collected from standard financial reports issued by 75 firms listed in the "Differentiated Levels of Corporate Governance" segment of the BM\&FBovespa stock market. Initially, using documental research, information was identified regarding derivative financial instruments the companies disclosed. The metrics adopted were based on the parameters established in the CPC 14 accounting standard (Financial instruments: recognition, measurement and disclosure). The preliminary analysis showed that none of the firms in the sample disclosed all the required items, and that only 11 of the 30 items were disclosed by over $50 \%$ of the firms. Subsequently, the association between company attributes and the level of disclosure was tested with Correspondence Analysis. 'Size' and 'Earnings'- but not "Debt" and "Profitability" - were significantly and positively associated with disclosure of information on derivative financial instruments.

Keywords: Disclosure. Derivative financial instruments. Correspondence analysis.

\section{INTRODUÇÃO}

Disclosure relaciona-se aos objetivos da Contabilidade na medida em que "garante informações diferenciadas para vários tipos de usuários" (IUDÍCIBUS, 2004, p. 123), subsidiando-os no processo decisório. Dentre as várias informações que podem e devem ser prestadas aos usuários, estão aquelas relacionadas aos instrumentos financeiros derivativos, os quais, tendo em vista suas características peculiares, podem tanto proporcionar grande alavancagem à empresa quanto ocasionar-lhe grandes perdas, inclusive comprometendo a sua própria continuidade (FIPECAFI, 2010).

Acerca dos instrumentos financeiros, em consonância com o processo de convergência às normas contábeis internacionais, em 2008 o CPC emitiu o Pronunciamento Técnico CPC 14 - Instrumentos Financeiros: Reconhecimento, Mensuração e Evidenciação, o qual prevê, no item 59, as informações mínimas que as empresas devem divulgar acerca dos instrumentos financeiros derivativos (CPC, 2008). Esse pronunciamento tornou-se aplicável às demonstrações contábeis referentes aos exercícios de 2008 e 2009 (FIPECAFI, 2010), sendo, ao final de 2009, transformado na Orientação Técnica OCPC 03, a qual, segundo a CVM (2009), pode sozinha atender à maioria das entidades.
Também, ao final de 2009, foram emitidos os Pronunciamentos Técnicos CPCs 38, 39 e 40 , os quais tratam mais detalhadamente das operações envolvendo os instrumentos financeiros. Sobre esses novos pronunciamentos, a CVM (2009, p.1) dispõe que "apenas as companhias que tenham instrumentos mais sofisticados" precisarão consultá-los.

O Pronunciamento Técnico CPC 40, cuja vigência se iniciou em 2010, trata especificamente da evidenciação de informações acerca dos instrumentos financeiros, adicionando evidenciações mais complexas e sofisticadas, aplicáveis de forma marginal ao conjunto das sociedades de Capital Aberto.

Nesse contexto, a presente pesquisa limita-se a abranger o estudo da evidenciação de informações requeridas pelo CPC 14 nas demonstrações contábeis referentes ao exercício de 2009, atendo-se ao seu escopo de examinar a reação dos gestores às novas regulamentações contábeis.

O disclosure de informações pelas empresas pode se dar de forma tanto voluntária quanto compulsória, sendo que a primeira constitui uma ação proativa da entidade, geralmente advinda dos incentivos recebidos pelo administrador para divulgá-las, enquanto a segunda, por sua vez, decorre de ação reativa, oriunda de regulamentação que obriga a 
empresa a divulgar determinada informação (YAMAMOTO; SALOTTI, 2006). Entretanto, Welker (1995 apud MURCIA, 2009, p. 30) ressalta que, apesar dos esforços dos órgãos reguladores, as companhias possuem discricionariedade na determinação do escopo, do conteúdo, do período e da forma de evidenciar informações aos usuários externos.

Destarte, é possível que, mesmo havendo a obrigação da divulgação de informações acerca dos instrumentos financeiros derivativos, algumas empresas não as tenham divulgado devido ao fato de ser recente a edição do CPC 14, bem como devido à complexidade de tais instrumentos e aos elevados custos associados a essa divulgação.

Pesquisas anteriores relacionaram $o$ disclosure praticado pelas empresas com os incentivos econômicos, valendo ressaltar os estudos de Lanzana (2004), Malacrida e Yamamoto (2006), Costa, Goldner e Galdi (2007), Lima (2007), Pereira et al. (2008), Murcia e Santos $(2009,2010)$ e Cruz e Lima (2010). Dentre as variáveis econômicas abordadas nos referidos estudos, destacam-se Tamanho, Lucro, Rentabilidade, Desempenho, Custo de Capital, Endividamento e Governança Corporativa, todas positivamente relacionadas ao disclosure no citado grupo de pesquisas.

No presente estudo, optou-se por estudar as seguintes variáveis: Tamanho, Lucro, Rentabilidade e Endividamento. A variável Tamanho teria uma associação positiva com disclosure na medida em que empresas maiores possuem maior demanda dos stakeholders por informações, além de maiores departamentos de contabilidade e de uma maior diluição dos custo de disclosure (MURCIA, 2009).

A relação positiva do disclosure com as variáveis de desempenho financeiro, Lucro e Rentabilidade, dar-se-ia em função do interesse dos administradores em reportar melhores resultados aos acionistas e partes interessadas (PEREIRA et al, 2008). No que se refere à variável Endividamento, a associação positiva se justificaria já que empresas mais endividadas são pressionadas a manterem um nível de divulgação mais transparente com o mercado, a fim de atender às exigências dos credores (FIGUEREDO, FAMÁ, SILVEIRA, 2005).

Assim, a pesquisa procura responder à seguinte questão: $\mathrm{O}$ nível de observância às práticas de divulgação acerca dos instrumentos financeiros derivativos está associado a incentivos decorrentes de características econômicas das empresas brasileiras de Capital Aberto?

Tendo em vista os custos envolvidos com o disclosure e a busca de eficiência informacional por empresas com melhor desempenho, tem-se como hipótese que maior nível de disclosure de informações acerca dos instrumentos financeiros derivativos está positivamente associado a incentivos econômicos relativos ao tamanho, ao desempenho financeiro e ao endividamento das empresas brasileiras de Capital Aberto.

O objetivo da pesquisa, portanto, é verificar a existência de associação entre a divulgação de informações acerca de instrumentos financeiros derivativos e características econômicas de sociedades brasileiras de Capital Aberto.

Para tanto, realizou-se Análise de Conteúdo das notas explicativas das demonstrações financeiras padronizadas referentes ao exercício de 2009 das empresas selecionadas, com base em métrica definida a partir dos dispositivos contidos no CPC 14. Em seguida, os dados foram analisados por meio da técnica de Análise de Correspondência.

A relevância da pesquisa pode ser caracterizada pela escassez de pesquisas acerca da evidenciação de informações sobre instrumentos financeiros derivativos à luz do CPC 14 , destacando-se, apenas, as pesquisas de Murcia (2009), que analisou essa evidenciação com dados do exercício 2008; Lima et al. (2010), que analisaram apenas seis itens de evidenciação requeridos no CPC 14; Zani, Zanini e Zani (2010) que estudaram, apenas, cinco empresas e Toneto Filho e Fregonesi (2010) que verificaram somente, o setor de 
alimentos processados, totalizando dezoito empresas, referentes ao exercício 2008. Foram verificados, ainda, outros estudos envolvendo a temática derivativos, mas antes da introdução do CPC 14 (DARÓS; BORBA, 2005, MOREIRA; NYAMA; SANTANA, 2006).

$\mathrm{O}$ presente estudo inova em relação a pesquisas anteriores por analisar todos os requisitos de divulgação previstos no CPC 14, bem como por utilizar todas as empresas dos Níveis Diferenciados de Governança Corporativa da BM\&FBovespa. O estudo contribui, ainda, com uma estrutura ideal de disclosu- re, já que possibilita observar, em relação ao ponto estudado, o grau de evidenciação das empresas brasileiras.

A pesquisa foi estruturada em cinco tópicos, incluída essa introdução. No segundo tópico é apresentada a revisão de literatura, sendo discutidas as temáticas determinantes de disclosure e disclosure de instrumentos financeiros derivativos. O terceiro e o quarto tópicos abordam, respectivamente, a metodologia utilizada na pesquisa e os resultados encontrados. O tópico derradeiro traz as considerações finais.

\section{REFERENCIAL TEÓRICO}

\subsection{Determinantes de disclosure}

O disclosure constitui um compromisso inalienável da Contabilidade com seus próprios objetivos (LOPES; MARTINS, 2005), tendo a finalidade de atender às necessidades de informações de seus usuários no processo decisório. A informação contábil divulgada deve possuir características essenciais, como relevância: confiabilidade, uniformidade, consistência e comparabilidade (YAMAMOTO; SALOTTI, 2006). Segundo Iudícibus (2004), toda informação contábil deve ser, ao mesmo tempo, adequada, justa e plena.

Conforme Yamamoto e Salotti (2006), as informações contábeis são disponibilizadas para os usuários por meio de demonstrações contábeis tradicionais, notas explicativas e outras formas alternativas, como demonstrações complementares e relatórios da administração. A essas, Iudícibus (2004) acrescenta, ainda, a informação entre parênteses, os quadros e demonstrações suplementares e os comentários do auditor. As notas explicativas evidenciam as qualificações e restrições de certos itens, detalham informações e franqueiam informações quantitativas e descritivas de valor secundário (HENDRIKSEN; BREDA, 1999).

O disclosure influencia o comportamento dos investidores, ao afetar a sua percepção em relação ao risco da companhia, assim como a percepção dos gestores, que decidirão o nível de evidenciação tomando por base o custo a ser incorrido para fornecer as informações (CRUZ; LIMA, 2010). Para auxiliar nesse processo informacional, conforme Lopes e Martins (2005), a Contabilidade deve guardar estreita relação com a realidade econômica, sob pena de perder sua utilidade para os agentes.

No âmbito do mercado de capitais, o disclosure reduz a assimetria informacional entre os agentes participantes, por meio da evidenciação de informações relevantes sobre o valor e o desempenho das companhias (LANZANA, 2004; PEREIRA et al. 2008, MURCIA; SANTOS, 2009).

Conforme Verrechia (2001), os estudos sobre disclosure podem ser agrupados em três grandes linhas de pesquisa: Association-based Disclosure, Discretionary-based Disclosure e Efficiency-based Disclosure. A primeira investiga a relação entre a divulgação de determinada informação e o comportamento dos investidores; a segunda procura identificar os motivos que levam a empresa a divulgar determinadas informações; a terceira estuda "a existência de algumas formas de divulgação que promovem a eficiência da divulgação, ou seja, são preferi- 
das incondicionalmente" (YAMAMOTO; SALOTTI, 2006, p. 84).

Pesquisas, geralmente, relacionam a divulgação voluntária de informações pelas empresas com a existência de maiores incentivos econômicos. Lima (2007) verificou que um maior nível de disclosure resulta em um menor custo de capital de terceiros. Pereira et al. (2008) observaram uma associação positiva entre o nível de disclosure e as variáveis lucro, tamanho da empresa, adesão a um dos Níveis Diferenciados de Governança Corporativa da BM\&FBovespa e a presença de acionistas controladores. Cruz e Lima (2010) constataram que a reputação corporativa possui uma associação positiva com o disclosure voluntário, encontrando o mesmo resultado para a variável tamanho.

Murcia e Santos (2009) verificaram que empresas maiores, pertencentes ao setor elétrico, com American Depositary Receipts (ADR) nos níveis II e III da Bolsa de Nova Iorque (NYSE) e listadas nos Níveis Diferenciados de Governança Corporativa da BM\&FBovespa, possuem um maior nível de disclosure voluntário. Posteriormente, referidos autores realizaram estudo semelhante abrangendo um período maior e uma métrica de disclosure mais abrangente e, contrapondo os achados anteriores, verificaram que tamanho, governança corporativa e internacionalização não são variáveis significativas para explicar um maior nível de disclosure, o qual foi significativamente explicado pelas variáveis setor elétrico, origem de controle, rentabilidade, desempenho, auditoria e endividamento (MURCIA; SANTOS, 2010).

Lanzana (2004) observou que empresas de controle privado nacional, maiores, com maior nível de endividamento, mais bem avaliadas pelo mercado e com maior desempenho, tendem a apresentar maior nível de transparência. Malacrida e Yamamoto (2006) concluíram que um maior nível de evidenciação de informações resulta em uma menor volatilidade das ações. O estudo de
Costa, Goldner e Galdi (2007) indica que a independência do conselho de administração, o tamanho, a listagem das ações no mercado de capitais, a participação nos Níveis Diferenciados de Governança Corporativa da BM\&FBovespa, bem como a emissão de ADRs na Bolsa de Nova Iorque influenciam o disclosure dos maiores bancos brasileiros.

De forma geral, as pesquisas supracitadas encontraram relação positiva entre o disclosure das empresas e determinadas características delas, de forma recorrente por: tamanho, lucro, rentabilidade e endividamento, características elencadas no presente estudo.

\subsection{Disclosure de instrumentos financeiros derivativos}

Instrumento financeiro é um contrato que origina um ativo financeiro em uma entidade e um passivo financeiro ou título patrimonial em outra (CPC, 2008). Dentre as espécies de instrumento financeiro, incluem-se os derivativos, "instrumentos financeiros de uma classe especial” (FIPECAFI, 2010, p. 110), cujo preço de mercado deriva de outro ativo ou contrato (ASSAF NETO, 2009).

Para ser classificado como derivativo, o instrumento financeiro deve acumular as seguintes características: a) alterar seu valor em resposta às mudanças na taxa de juros específica, no preço de commodities, na taxa de câmbio etc.; b) possuir um investimento inicial nulo ou muito pequeno e c) ser liquidado em uma data futura (CPC, 2008). A segunda característica possibilita que os derivativos proporcionem grande alavancagem à empresa (FIPECAFI, 2010).

Murcia (2009) leciona que a gestão de riscos feita pelas empresas utilizando-se de derivativos consiste em transferir os riscos indesejados à outra parte mais habilitada a correr tais riscos. A utilização de derivativos possibilita, por exemplo, proteger a empresa de riscos com obrigações futuras em moeda estrangeira e de altas na cotação de insumos necessários à sua produção, como petróleo 
(ASSAF NETO, 2009). Mas, como destaca Perlingeiro (2009), os instrumentos derivativos podem causar prejuízos significativos às instituições envolvidas.

Percebe-se, assim, que dada a natureza dos instrumentos financeiros derivativos, deve haver cuidado redobrado quando da contabilização e divulgação de informações acerca dessas transações. Contudo, num primeiro momento, os itens relativos aos instrumentos financeiros derivativos "eram considerados itens fora do balanço", impossibilitando aos usuários o conhecimento acerca do risco que a instituição estava assumindo. Mas, após a ocorrência de grandes perdas, como nos casos Showa Shell Sekiyu, no Japão; Metallgesellschaft, na Alemanha; e Banco Barings, no Reino Unido, os instrumentos financeiros derivativos passaram a receber atenção especial dos legisladores e órgãos reguladores, como o Financial Accounting Standards Board (FASB) e o International Accounting Standars Board (IASB) (AMARAL, 2003, p. 75).

No Brasil, as operações com instrumentos financeiros derivativos tornaram-se mais evidentes nos últimos anos. Diante de uma nova realidade financeira, "empresas comerciais e industriais, antes ausentes do mercado de derivativos, começaram a se tornar players importantes do mercado". Em 2008, a grande desvalorização cambial do real em relação ao dólar norte-americano levou grandes empresas brasileiras a amargar significativas perdas com operações com derivativos, trazendo "à tona a importância de um adequado processo de contabilização dessas operações" (FIPECAFI, 2010, p. 111).

Murcia (2009) destaca o caso da Aracruz, cujas operações com derivativos, realizadas em 2008, geraram um passivo não circulante de R\$ 8.744.231,00 no balanço consolidado, bem como o da Vicunha Têxtil, que, também, incorreu em prejuízos envolvendo instrumentos financeiros derivativos no mesmo período. O referido autor relata que, como os prejuízos envolvendo instrumentos financei- ros derivativos "são notícias ruins para o mercado, os gestores, muitas vezes, não possuem incentivos para divulgar, voluntariamente, essas informações" (MURCIA, 2009, p. 45), uma vez que, não sendo obrigatória a divulgação, por que divulgar uma notícia ruim?

Em consonância com o processo de convergência das normas e práticas contábeis brasileiras aos padrões internacionais, o Comitê de Pronunciamentos Contábeis emitiu o Pronunciamento Técnico CPC 14, o qual define as informações mínimas que as empresas devem divulgar acerca dos instrumentos financeiros derivativos (CPC, 2008).

Pesquisas anteriores, também, investigaram as práticas de disclosure relativas aos instrumentos financeiros derivativos. Utilizando métrica oriunda da Deliberação CVM $\mathrm{n}^{\circ}$. 235, Darós e Borba (2005) concluíram que a grande maioria das empresas não atende às determinações da CVM no sentido de evidenciar, de forma clara, concisa e objetiva, as informações referentes às suas operações envolvendo derivativos.

Moreira, Nyama e Santana (2006) verificaram que, nas demonstrações contábeis publicadas no Brasil, não há menção do valor justo dos derivativos nem do método de seu cálculo; dos riscos de juros incorridos pela companhia e de dados quantitativos acerca dos riscos de mercado.

Mais recentemente, Murcia (2009) investigou o assunto à luz da Deliberação CVM $\mathrm{n}^{\circ}$. 566, que aprovou o CPC 14 . Os resultados encontrados demonstram que, em 2008, (a) a maioria das empresas informou o valor justo dos seus derivativos, mas não comentou os critérios de avaliação e mensuração utilizados no cômputo desses valores; (b) menos da metade das empresas tratou do efeito das operações de hedge e não hedge no resultado e (c) aproximadamente $70 \%$ das empresas evidenciaram os ganhos e perdas com derivativos no período. Apesar do não atendimento integral às exigências definidas no CPC 14, já se observa uma mudança de postura por 
parte das empresas, no tocante ao disclosure de derivativos.

Estudando os incentivos determinantes do processo de convergência contábil no Brasil, Lima et al. (2010) construíram uma métrica composta, dentre outros pontos, por seis itens referentes aos instrumentos financeiros derivativos, e verificaram que empresas maiores, mais expostas ao mercado internacional, e que possuem maiores necessidades de financiamento, são mais propensas a adotar os novos dispositivos, em comparação com aquelas que não dispõem dos mesmos incentivos.

Zani, Zanini e Zani (2010) pesquisaram acerca do cumprimento das normas legais e da transparência das empresas para com seus acionistas em relação ao risco assumido por meio de operações com derivativos cambiais, utilizando como amostra as empresas Aracruz, Perdigão, Sadia, Suzano e Votorantim. Referidos autores verificaram que a Instrução CVM no. 235 não vinha sendo observada em relação à explicação da utilização dos derivativos e que as empresas só passaram a, real- mente, informar as operações após os eventos com derivativos tóxicos e a publicação da Deliberação CVM nº. 550, que passou a exigir das empresas maior número de informações.

Tonetto Filho e Fregonesi (2010) analisaram a relação entre a variação dos níveis de endividamento e liquidez e o nível de divulgação sobre instrumentos financeiros, arrendamentos mercantis, provisões e contingências. Referidos autores constataram uma baixa variação nos índices de liquidez e endividamento, bem como uma melhora na divulgação dos itens entre 2007 e 2008, ressaltando, porém, que essa divulgação ainda está longe do alinhamento às normas internacionais.

Logo, em relação aos instrumentos financeiros derivativos, o incentivo à divulgação, decorrente da existência das normas, pode não ser suficiente para determinar a total observância ao disclosure pelas empresas, uma vez que, mesmo diante da obrigatoriedade, muitos outros fatores podem afetar a divulgação de informações, constituindo-se em incentivos econômicos e institucionais ao maior nível de disclosure.

\section{METODOLOGIA}

A pesquisa caracteriza-se como descritiva, adotando-se, para atender ao objetivo proposto, abordagem quantitativa, com procedimentos documentais, utilizando-se de dados secundários provenientes das notas explicativas às demonstrações contábeis de 2009, publicadas pelas empresas listadas nos Níveis Diferenciados de Governança Corporativa da $\mathrm{BM} \& \mathrm{FBovespa}$.

Inicialmente, por meio de pesquisa documental, foram identificadas as informações acerca dos instrumentos financeiros derivativos divulgadas pelas empresas, sendo, em seguida, realizado o teste estatístico Análise de Correspondência (ANACOR) para se verificar a associação entre o nível de disclosure de tais informações e as características econômicas das empresas. Destaque-se que to- das as informações foram colhidas no portal eletrônico da BM\&FBovespa em dezembro de 2010.

Foram examinadas as demonstrações contábeis das empresas listadas nos Níveis Diferenciados de Governança Corporativa da BM\&FBovespa, totalizando 165 empresas. Optou-se por constituir a amostra pelas empresas referidas entendendo-se que essas se declaram aderentes a boas práticas de governança corporativa, se comparadas às demais empresas listadas; ademais, conforme pesquisas de Lanzana (2004) e Gallon, Beuren e Hein (2007), já se havia identificado uma relação positiva entre níveis de disclosure e os segmentos de governança corporativa listados na BM\&FBovespa.

Para constituir a amostra da pesquisa 
(Quadro1), classificada como nãoprobabilística, excluíram-se do universo considerado: (a) as empresas classificadas no setor de atuação financeiro e outros da BM\&FBovespa, por adotarem normatizações diferenciadas acerca dos instrumentos financeiros derivativos; (b) as empresas que explicitaram nas notas explicativas às demonstrações financeiras padronizadas não possuir instru- mentos financeiros derivativos ao final do exercício de 2009; (c) as empresas Renova e Redentor, cujas demonstrações financeiras padronizadas não foram disponibilizadas no portal eletrônico da BM\&Bovespa e (d) a empresa TEREOS, que, embora listada no segmento Novo Mercado da BM\&FBovespa na data da coleta dos dados, somente passou a operar nessa Bolsa em 2010.

Quadro 1 Composição da amostra de pesquisa

\begin{tabular}{|l|c|}
\hline População da Pesquisa & 165 \\
\hline Empresas do setor financeiro e outros & $(35)$ \\
\hline Empresas que não possuíam instrumentos financeiros derivativos em 31/12/2009 & $(52)$ \\
\hline $\begin{array}{l}\text { Empresas cujas demonstrações financeiras padronizadas não foram disponibilizadas no portal eletrônico } \\
\text { da BM\&FBovespa }\end{array}$ & $(2)$ \\
\hline Empresa que não operava em 2009 & $(1)$ \\
\hline AMOSTRA VÁLIDA & 75 \\
\hline
\end{tabular}

A amostra final da pesquisa totalizou 75 companhias, cujos dados foram coletados e catalogados utilizando-se métrica desenvolvida a partir do CPC 14, que dispõe acerca das evidenciações mínimas sobre os instrumentos financeiros derivativos que devem constar nas notas explicativas às demonstrações contábeis publicadas pelas empresas (CPC, 2008). Foram elencados 30 itens de evidenciação a serem observados pelas empresas.

Quando da análise dos dados, para cada item de evidenciação, foi atribuído o valor 1 (um) quando a informação requerida estava presente e o valor 0 (zero), no caso contrário. Considerou-se que uma boa divulgação pressupõe que, não ocorrendo o evento objeto de divulgação, a empresa deve divulgar a não ocorrência. Desse modo, nos casos em que as companhias não fizeram nenhuma menção aos instrumentos financeiros derivativos, foi considerado o não cumprimento das práticas exigidas, atribuindo-se o valor 0 para todos os 30 itens de divulgação.

$\mathrm{Na}$ construção da métrica composta a partir do CPC 14, intentou-se desmembrar ao máximo os itens de evidenciação para que não houvesse margem para atendimento parcial a qualquer dos itens; ainda assim, houve, marginalmente, situações em que se defrontou com atendimento parcial ao requisito, atribuindo-se o valor 1 . A incidência de tal fato foi mínima, não implicando em viés significante aos resultados da pesquisa.

Destarte, quando era requerida determinada informação, como "valor e tipo de margens dadas em garantia", considerou-se que, caso não tivesse efetuado garantia em suas operações com derivativos, a empresa deveria informar a não ocorrência. Além disso, divulgações como "a companhia e suas controladas não efetuam aplicações de caráter especulativo, em derivativos ou quaisquer outros ativos de risco" não foram consideradas como clara menção da inexistência de instrumentos financeiros derivativos, uma vez que ressaltam, apenas, que a empresa não utilizava derivativos para fins especulativos, motivo pelo qual tais empresas foram incluídas na amostra de pesquisa, recebendo a respectiva nota de divulgação.

Foi criada a variável Nota de Disclosure, resultante da soma dos valores atribuídos aos itens de evidenciação investigados. Assim, a 
variável Nota de Disclosure de cada empresa recebeu um valor inteiro entre os extremos 0 e 30. O valor 0 indicou que a empresa não observou nenhuma das divulgações obrigatórias, enquanto a nota 30 apontou que a empresa cumpriu todas as determinações do CPC 14.

Após coletados e catalogados os dados, procurou-se verificar a associação entre a variável Nota de Disclosure e características econômicas das empresas, sendo elencadas variáveis referentes a tamanho e desempenho, uma vez que se espera que haja incentivos ao disclosure para empresas que, para atender aos investidores e garantir menor custo de capital e menor risco, apresentem melhor desempenho e sejam mais expostas em virtude de seu tamanho.

Desse modo, tomando por base estudos anteriores, foram selecionadas as variáveis: (i) Tamanho; (ii) Lucro; (iii) Rentabilidade e (iv) Endividamento, para as quais foram utilizadas as proxies explicitadas no Quadro 2, coletadas nas demonstrações financeiras padronizadas disponibilizadas no portal eletrônico da BM\&FBovespa.

Quadro 2 Variáveis representativas dos incentivos econômicos

\begin{tabular}{|l|l|}
\hline VARIÁVEL & PROXY \\
\hline Tamanho & $=$ Ativo Total \\
\hline Lucro & $=$ Lucro Líquido \\
\hline Rentabilidade & $=$ Lucro Líquido / Patrimônio Líquido (ROE) \\
\hline Endividamento & $=$ Passivo Oneroso / Ativo Total \\
\hline
\end{tabular}

Para o processamento dos dados e a posterior análise dos resultados foi utilizada a técnica estatística multivariada Análise de Correspondência (Anacor), com o suporte do software Statistical Package for the Social Sciences (SPSS 15). De acordo com Fávero et al. (2009, p. 272), a Anacor "é uma técnica que exibe as associações entre um conjunto de variáveis categóricas não métricas em um mapa perceptual, permitindo, dessa maneira, um exame visual de qualquer padrão ou estrutura nos dados", sendo as associações entre as variáveis inferidas com base nas respectivas posições no mapa perceptual e a análise feita por meio do exame das relações de proximidade geométrica das categorias das variáveis.

Devido ao fato de a Anacor utilizar variáveis nãométricas, foi necessário transformar as variáveis em elementos nãométricos. Assim, a variável Nota de Disclosure, bem como as variáveis que representam incentivos econômicos ao disclosure (Tamanho, Lucro, Endividamento e Rentabilidade) foram distribuídas em três grupos com mesma quantidade, ou seja, 25 empresas, segmentadas, assim, em MENOR, MÉDIO e MAIOR, de acordo com os respectivos valores apresentados.
Para a operacionalização da Anacor, realizou-se, inicialmente, o teste Qui-quadrado, para averiguar a dependência entre as variáveis, uma vez que a relação de dependência é requisito indispensável para a utilização da Anacor. Para tanto, utilizou-se o nível de significância 5\%, o que corresponde a $95 \%$ de segurança na fidedignidade dos resultados.

Posteriormente, aplicou-se o teste Anacor propriamente dito, buscando aceitar ou refutar a hipótese da pesquisa (associação entre nível de disclosure e atributos econômicos das sociedades de Capital Aberto), utilizando-se dos seguintes testes:

$\mathrm{H}_{1}$ : o nível de disclosure dos instrumentos financeiros derivativos está associado positivamente ao Tamanho;

$\mathrm{H}_{2}$ : o nível de disclosure dos instrumentos financeiros derivativos está associado positivamente ao Lucro;

$\mathrm{H}_{3}$ : o nível de disclosure dos instrumentos financeiros derivativos está associado positivamente à Rentabilidade;

$\mathrm{H}_{4}$ : o nível de disclosure dos instrumentos financeiros derivativos está associado positivamente ao Endividamento. 


\section{ANÁLISE DOS RESULTADOS}

Após a análise das notas explicativas às demonstrações financeiras padronizadas, foi possível observar o grau de cumprimento,

pelas empresas pesquisadas, no que tange às divulgações obrigatórias definidas no CPC 14 (Tabela 1).

Tabela 1 Disclosure de informações sobre instrumentos financeiros derivativos

\begin{tabular}{|c|c|c|}
\hline \multirow[t]{2}{*}{ Item observado } & \multicolumn{2}{|c|}{$\begin{array}{c}\text { Frequência } \\
\text { observada }\end{array}$} \\
\hline & $\mathbf{N}^{\mathbf{o}}$ & $\%$ \\
\hline (a) Política de utilização & 61 & 81,3 \\
\hline $\begin{array}{l}\text { (b) Objetivos e estratégias de gerenciamento de riscos, particularmente a política de proteção patri- } \\
\text { monial (hedge) }\end{array}$ & 27 & 36,0 \\
\hline (c1) Riscos associados a cada estratégia de atuação no mercado & 52 & 69,3 \\
\hline (c2) Adequação dos controles internos e parâmetros utilizados para o gerenciamento desses riscos & 23 & 30,7 \\
\hline (c3) Os resultados obtidos em relação aos objetivos propostos & 0 & 0,0 \\
\hline (d1) O valor justo de todos os derivativos contratados & 51 & 68,0 \\
\hline $\begin{array}{l}\text { (d2) Os critérios de avaliação e mensuração, métodos e premissas significativas aplicadas na apura- } \\
\text { ção do valor justo }\end{array}$ & 44 & 58,7 \\
\hline \multicolumn{3}{|l|}{ (e) Valores registrados em contas de ativo e passivo segregados, por: } \\
\hline (e1) Categoria & 15 & 20,0 \\
\hline (e2) Risco & 5 & 6,7 \\
\hline (e3) Estratégia de atuação no mercado & 0 & 0,0 \\
\hline $\begin{array}{l}\text { (e4) Aqueles com o objetivo de proteção patrimonial (hedge) e aqueles com o propósito de negocia- } \\
\text { ção }\end{array}$ & 49 & 65,3 \\
\hline \multicolumn{3}{|l|}{ (f) Valores agrupados por: } \\
\hline (f1) Ativo & 19 & 25,3 \\
\hline (f2) Indexador de referência & 16 & 21,3 \\
\hline (f3) Contraparte & 44 & 58,7 \\
\hline (f4) Local de negociação (bolsa ou balcão) ou de registro & 25 & 33,3 \\
\hline (f5) Faixa de vencimento & 47 & 62,7 \\
\hline \multicolumn{3}{|l|}{ (f6) Destacados: } \\
\hline (f6.1) Os valores de referência & 45 & 60,0 \\
\hline (f6.2) De custo & 17 & 22,7 \\
\hline (f6.3) Valor justo & 51 & 68,0 \\
\hline (f6.4) Risco da carteira & 4 & 5,3 \\
\hline (g) Ganhos e perdas no período & 47 & 62,7 \\
\hline (g1) Ganhos e perdas no período, agrupados pelas principais categorias de riscos assumidos & 13 & 17,3 \\
\hline (g2) Ganhos e perdas no período, segregados aqueles registrados no resultado & 25 & 33,3 \\
\hline (g3) Ganhos e perdas no período, segregados aqueles registrados no patrimônio líquido & 11 & 14,7 \\
\hline $\begin{array}{l}\text { (h) Valores e efeito no resultado do período de operações que deixaram de ser qualificadas para a } \\
\text { contabilidade de operações de proteção patrimonial (hedge) }\end{array}$ & 8 & 10,7 \\
\hline $\begin{array}{l}\text { (h1) Valores e efeito no resultado do período daqueles montantes transferidos do patrimônio líquido } \\
\text { em decorrência do reconhecimento contábil das perdas e dos ganhos no item objeto de hedge }\end{array}$ & 1 & 1,3 \\
\hline $\begin{array}{l}\text { (i) Principais transações e compromissos futuros objeto de proteção patrimonial (hedge) de fluxo de } \\
\text { caixa }\end{array}$ & 9 & 12,0 \\
\hline
\end{tabular}


continuação

\begin{tabular}{|c|c|c|}
\hline $\begin{array}{l}\text { (i1) Principais transações e compromissos futuros objeto de proteção patrimonial (hedge) de fluxo de } \\
\text { caixa, destacados: }\end{array}$ & & \\
\hline (i1.1) Os prazos para o impacto financeiro previsto & 5 & 6,7 \\
\hline (i1.2) $\mathrm{O}$ valor e tipo de margens dadas em garantia & 38 & 60,7 \\
\hline (i1.3) Razões pormenorizadas de eventuais mudanças na classificação dos instrumentos financeiros & 0 & 0,0 \\
\hline
\end{tabular}

Na Tabela 1, verifica-se que, dos 30 itens de evidenciação, apenas 11 tiveram uma frequência de divulgação superior a 50\%, sendo evidenciado por mais da metade das 75 companhias. $\mathrm{O}$ item mais divulgado foi aquele referente à "política de utilização" dos instrumentos financeiros derivativos, evidenciado por 61 das 75 empresas estudadas, representando $81,3 \%$ da amostra.

Esse fato corrobora o estudo de Murcia (2009), que apontou como itens mais divulgados pelas empresas a "política de utilização" e os "objetivos e estratégias de gerenciamento de riscos". Já na pesquisa de Lima et al. (2010), foi observado um índice de divulgação da "política de utilização" correspondente a 95,7\% pelas empresas da amostra, cabendo destacar que esse estudo utilizou como amostra de pesquisa apenas as 50 empresas listadas no Índice Ibovespa em dezembro de 2009.

$\mathrm{O}$ item "objetivos e estratégias de gerenciamento de riscos", o segundo mais divulgado pelas empresas analisadas por Murcia (2009), foi divulgado por apenas 36\% das empresas objeto da presente pesquisa. Essa divergência pode ser explicada pelo fato de o estudo de Murcia (2009) ter utilizado como amostra as 100 maiores empresas, enquanto a presente pesquisa estudou todas as empresas dos Níveis Diferenciados de Governança Corporativa da BM\&FBovespa, bem como pelo fato de Murcia (2009) haver excluído de sua amostra as empresas que não fizeram nenhuma divulgação acerca dos instrumentos financeiros derivativos, ao contrário da presente pesquisa, em que tais empresas obtiveram a nota 0 .

Ainda em relação aos itens mais divulgados, destacam-se "riscos associados a cada estratégia de atuação no mercado", divulgado por 52 ou $69,3 \%$ das empresas integrantes da amostra, "valor justo" e "valor justo de todos os derivativos contratados", divulgados por 51 empresas (68\%) e "ganhos e perdas no período" evidenciado por 47 (62,7\%).

No que tange ao "valor justo", destaquese que, embora $68 \%$ das empresas o tenham divulgado, apenas 58,7\% evidenciaram "os critérios de avaliação e mensuração, métodos e premissas significativas aplicadas na apuração do valor justo". Como responsáveis por tal diferença, destacam-se tanto a ausência total da divulgação da informação por determinadas empresas, quanto a existência de informações vagas, não condizentes com o solicitado pela norma, que requer a divulgação de “(...) métodos e premissas significativas aplicadas na apuração do valor justo" (CPC 14) (grifo nosso).

Destaque-se que Lima et al. (2010), também, encontraram índices diferentes quanto à divulgação do valor justo. Os autores verificaram que o valor justo dos derivativos foi evidenciado por $97,7 \%$ das 50 empresas integrantes da amostra, enquanto o item referente à "divulgação dos critérios de mensuração a valor justo dos derivativos contratados" foi evidenciado por $91,1 \%$ da referida amostra.

Outro ponto relevante refere-se ao fato de os itens "resultados obtidos em relação aos objetivos propostos", "valores registrados em contas de ativo e passivo segregados por estratégia de atuação no mercado" e "razões pormenorizadas de eventuais mudanças na classificação dos instrumentos financeiros" não terem sido divulgados por nenhuma das 75 empresas. Quanto a esse último item, Tonetto Filho e Fregonesi (2010), também, não identificaram nenhuma divulgação pelas empresas integrantes da amostra de pesquisa nos exercícios de 2007 e 2008, o que indica uma possível tendência de não divulgação desse evento 
pelas empresas, provavelmente, em alguns casos, por realmente não ter ocorrido.

Dentre os itens menos divulgados, destacam-se "risco da carteira", divulgado por apenas quatro empresas (5,3\%); "principais transações e compromissos futuros objeto de proteção patrimonial (hedge) de fluxo de caixa, destacados os prazos para o impacto financeiro previsto", e "valores registrados em contas de ativo e passivo segregados, por risco", divulgados por apenas cinco (6,7\%); e "valores e efeito no resultado do período daqueles montantes transferidos do patrimônio líquido em decorrência do reconhecimento contábil das perdas e dos ganhos no item objeto de hedge", divulgado por apenas uma empresa, essa pertencente ao Nível 1 de Governança Corporativa da BM\&FBovespa.

A variável Nota de Disclosure, que sintetiza o grau de cumprimento das determinações de divulgação pelas companhias, está explicitada na Tabela 2.

Tabela 2 Notas de Disclosure das informações sobre instrumentos financeiros derivativos

\begin{tabular}{c|c|c}
\hline $\begin{array}{c}\text { Nota de } \\
\text { disclosure }\end{array}$ & $\begin{array}{c}\mathbf{N}^{\circ} \text { de } \\
\text { companhias }\end{array}$ & $\begin{array}{c}\% \text { de } \\
\text { companhias }\end{array}$ \\
\hline $0(0 \%)$ & 7 & 9,3 \\
\hline $2(7 \%)$ & 5 & 6,6 \\
\hline $4(13 \%)$ & 1 & 1,3 \\
\hline $6(20 \%)$ & 2 & 2,6 \\
\hline $7(23 \%)$ & 6 & 8,0 \\
\hline $8(27 \%)$ & 8 & 10,7 \\
\hline $9(30 \%)$ & 2 & 3,0 \\
\hline $10(33 \%)$ & 4 & 5,3 \\
\hline $11(37 \%)$ & 8 & 10,7 \\
\hline $12(40 \%)$ & 6 & 8,0 \\
\hline $13(43 \%)$ & 8 & 10,7 \\
\hline $14(47 \%)$ & 4 & 5,3 \\
\hline $15(50 \%)$ & 3 & 4,0 \\
\hline $16(53 \%)$ & 1 & 1,3 \\
\hline $17(57 \%)$ & 4 & 5,3 \\
\hline $18(60 \%)$ & 2 & 2,6 \\
\hline $19(63 \%)$ & 4 & 5,3 \\
\hline TOTAL & 75 & 100,0 \\
\hline
\end{tabular}

Vale observar que nenhuma das 75 empresas alcançou a nota máxima de divulgação, sendo que quatro companhias com maior disclosure evidenciaram 19 itens ou $63 \%$ do total de informações requeridas. Uma dessas companhias pertence ao Nível 2 de Governança Corporativa da BM\&FBovespa, enquanto as demais pertencem ao Novo Mercado. Sete empresas, ou seja, 9,3\%, não divulgaram nenhuma informação requerida acerca dos instrumentos financeiros derivativos, motivo pelo qual obtiveram a nota 0 . Uma dessas empresas pertence ao Nível $1 \mathrm{de}$ Governança Corporativa da BM\&FBovespa, outra, ao Nível 2, enquanto as demais pertencem ao Novo Mercado.

Outro fato que pode ser observado na Tabela 2 é que as notas 8, 11 e 13 foram obtidas pelo maior número de empresas ( 8 para cada nota), de maneira que apenas essas 3 notas reuniram 24 empresas. As notas 4 e 16 foram obtidas por apenas duas empresas (uma para cada nota).

Na operacionalização da Anacor, conforme já disposto, deve-se, primeiramente, utilizar o teste Qui-quadrado. Assim, a Tabela 3 apresenta os resultados do referido teste para cada uma das características econômicas consideradas.

Tabela 3 Teste Qui-quadrado

\begin{tabular}{l|c|c}
\hline Associações & N & p-value \\
\hline Nota de Disclosure x Tamanho & 75 & 0,002 \\
\hline Nota de Disclosure x Endividamento & 75 & 0,878 \\
\hline Nota de Disclosure x Lucro & 75 & 0,014 \\
\hline Nota de Disclosure x Rentabilidade & 75 & 0,308 \\
\hline
\end{tabular}

Verifica-se que somente para as variáveis Tamanho e Lucro pôde-se inferir sua relação com a variável Nota de Disclosure, uma vez que essas variáveis apresentaram significância estatística a níveis satisfatórios. Quanto às variáveis Endividamento e Rentabilidade não se visualizou associação entre elas e a variável Nota de Disclosure.

A associação entre as variáveis Nota de 
Disclosure e Tamanho é apresentada na Figura 1, pelo Mapa perceptual obtido. Constatase a relação positiva esperada pelo primeiro teste da pesquisa.

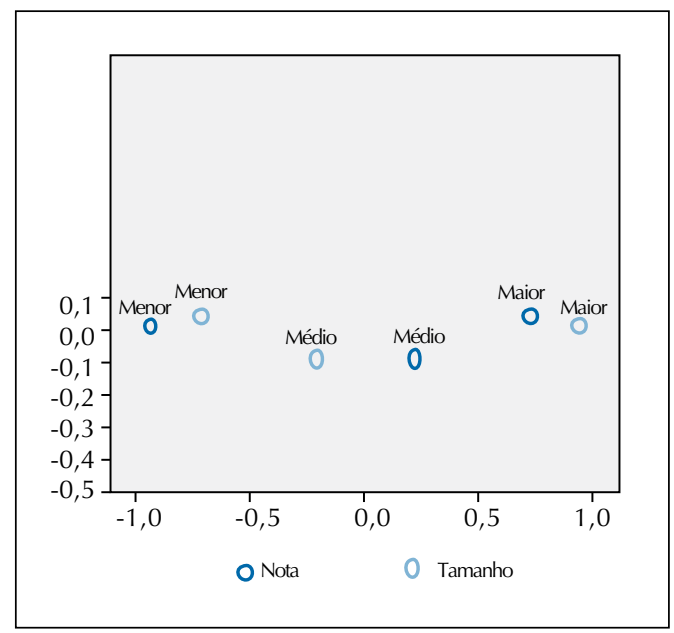

Figura 1 Mapa perceptual da Nota de Disclosure x Tamanho

A análise da Figura 1 enseja observar a proximidade entre as variáveis no mapa perceptual, constatando-se, assim, que um maior nível de disclosure das informações acerca dos instrumentos financeiros derivativos está associado a um maior tamanho da empresa; um tamanho médio está associado a um disclosure médio, e um tamanho menor está associado a um disclosure menor. Portanto, a partir da análise do mapa perceptual, o primeiro teste aponta para a aceitação da hipótese da pesquisa.

O teste estatístico Anacor foi, ainda, aplicado para verificar a associação entre as variáveis Nota de Disclosure e Lucro (Figura 2).

A análise da Figura 2 possibilita verificar uma proximidade positiva entre as variáveis no mapa perceptual, constatando-se, assim, que um maior nível de disclosure de informações acerca dos instrumentos financeiros derivativos está associado a um maior Lucro, não apontando o segundo teste para rejeitar, também aqui, a hipótese de pesquisa.

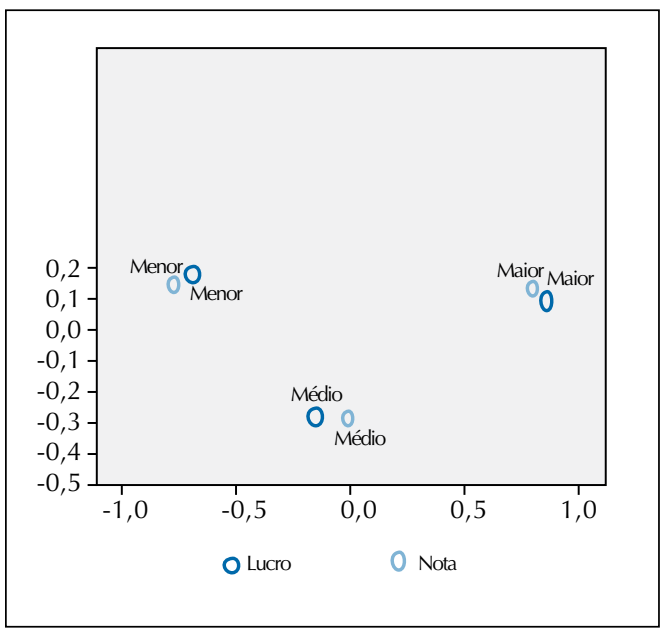

Figura 2 Mapa perceptual da Nota de Disclosure x Lucro

\section{CONCLUSÕES}

A pesquisa teve por objetivo verificar a existência de associação entre a divulgação de informações acerca de instrumentos financeiros derivativos e características econômicas de sociedades brasileiras de Capital Aberto, sendo elencadas características representativas de tamanho, endividamento e desempenho financeiro das empresas.

No cálculo da Nota de Disclosure das empresas, foi construída métrica de disclosure de informações acerca dos instrumentos financeiros derivativos a partir dos dispositivos do
CPC 14, sendo analisadas as notas explicativas de 75 empresas listadas nos Níveis Diferenciados de Governança Corporativa, do período de 2009.

Em análise preliminar verificou-se que apenas 11 dos 30 itens de evidenciação constantes da métrica foram divulgados por mais de $50 \%$ das companhias da amostra. Além disso, dessas 75 companhias, nenhuma apresentou todos os itens de evidenciação requeridos, sendo 19 o número máximo obtido por companhia. Tais resultados vão ao encontro 
do levantamento realizado pela CVM com o objetivo de verificar a aplicação dos primeiros 14 pronunciamentos emitidos pelo $\mathrm{Co}-$ mitê de Pronunciamentos Contábeis (CPC), o qual evidenciou que, nas demonstrações financeiras referentes ao segundo e terceiro trimestres de 2010, 40\% das empresas analisadas apresentaram falhas nos dados sobre derivativos, seja na forma definida pelas normas contábeis seja no quadro de sensibilidade exigido desde o fim de 2008 pela CVM (TORRES, 2011).

Posteriormente, foi aplicada a técnica de Análise de Correspondência (ANACOR), para investigar associação entre nível de disclosure e características econômicas das empresas capazes de incentivar-lhes maior nível de disclosure.

Nos resultados encontrados, não se verificou associação positiva e significante quanto às variáveis Endividamento e Rentabilidade, testes - terceiro e quarto - que conduzem à rejeição da hipótese pesquisa.

Uma possível justificativa para a ausência de associação entre o disclosure de informações acerca dos instrumentos financeiros derivativos e a variável Endividamento decorre da possibilidade de as empresas brasileiras estarem se financiando, basicamente, em moeda nacional, caso em que não necessitariam contratar derivativos para proteger-se do risco de financiarse em moeda estrangeira e, por esse motivo, não divulgam tais informações.

Quanto à variável Rentabilidade, essa não se mostrou com significância estatística, valendo dizer que a relativização da medida pelo PL (maior eficiência) não se apresenta como incentivo para o disclosure de derivativos.

No tocante às demais variáveis, constatou-se que (1) um maior nível de disclosure das informações sobre instrumentos financeiros derivativos está associado a um maior Tamanho e (2) a um maior Lucro, tomado em termos absolutos.
A primeira constatação corrobora as evidências da pesquisa realizada por Murcia e Santos (2009), ao observarem que maiores organizações apresentam maior disclosure, justificando que isso pode ser explicado pelo fato de elas possuírem maiores departamentos de contabilidade, dispondo, por conseguinte, de mais recursos para a preparação das demonstrações contábeis, o que pode influenciar o maior nível de disclosure das organizações. Além disso, confirma, ainda, os achados de Lanzana (2004), Costa, Golder e Galdi (2007), Pereira et al. (2008), Murcia e Santos (2009) e Cruz e Lima (2010), mas se contrapõe aos resultados da pesquisa de Murcia e Santos (2010).

Quanto à constatação de que um maior Lucro está associado a um maior disclosure, corrobora a pesquisa de Pereira et al. (2008), que, também, constatou que empresas com maiores lucros apresentam maior nível de disclosure.

Desse modo, a não rejeição da hipótese de pesquisa quanto às variáveis Tamanho e Lucro permite inferir que tais características conduzem a um maior disclosure, havendo uma preferência por maior eficiência informacional nas empresas mais expostas, pela sua escala, à demanda por informação pelos stakeholders; a transparência, também, é determinada por empresas com desempenho superior, somando-se, portanto, tal característica a outra de maior eficiência econômica.

Verificou-se, assim, que o nível de observância às práticas de divulgação acerca dos instrumentos financeiros derivativos está associado a incentivos decorrentes de características econômicas das empresas de Capital Aberto brasileiras; assim, a hipótese adotada não pode ser rejeitada - variáveis Tamanho e Lucro significantemente associadas ao nível de disclosure - carecendo-se de pesquisas adicionais com outros atributos econômicos e institucionais, que possam influenciar as decisões dos gestores dessas firmas a incre- 
mentar o nível de disclosure sobre os instrumentos financeiros derivativos.

Além disso, outros estudos podem, ainda, abordar a análise da qualidade das informações divulgadas sobre instrumentos financeiros derivativos e ampliar as observações, contemplando dados de demais exercícios e incluindo as empresas do mercado tradicional da BM\&FBovespa, não consideradas no presente estudo, podendo-se, ainda, confrontar os resultados obtidos em anos diferentes.

Sugere-se que outras pesquisas tratem dos demais pronunciamentos emitidos a respeito dos instrumentos financeiros derivativos, vigentes a partir do ano de 2010, quais sejam os
CPCs 38, 39 e 40, tendo em vista a importância desses instrumentos para o desenvolvimento do mercado de capitais e, consequentemente, para o desenvolvimento econômico do país.

Por fim, outros aspectos sobre o tema podem ser abordados, com técnicas estatísticas diversas, que possam melhor explicar a magnitude das medidas econômicas com o grau de disclosure comparado a outras economias; ainda pode ser investigada a variação temporal das variáveis, bem como o efeito de características institucionais influenciando o nível de disclosure, tal como participação em listagens diversas (Novo Mercado, Emissão de ADR, Setor Econômico, dentre outros).

\section{Referências}

AMARAL, Carlos Antônio Lopes Vaz do. Derivativos: o que são e a evolução quanto ao aspecto contábil. Revista Contabilidade \& Finanças, n. 32, p. 71-80, maio/ago. 2003. ASSAF NETO, Alexandre. Finanças corporativas e valor. 4. ed. São Paulo: Atlas, 2009.

COSTA, Fábio Moraes da; GOLDNER, Fábio; GALDI, Fernando Caio. Análise dos fatores que influenciam no disclosure dos maiores bancos brasileiros. In: CONGRESSO USP DE CONTABILIDADE E CONTROLADORIA, 7., 2007, São Paulo. Anais... São Paulo: USP, 2007. CD-ROM.

CPC. Comitê de Pronunciamentos Contábeis. CPC 14: Instrumentos financeiros: reconhecimento, mensuração e evidenciação. 2008. Disponível em: <http://www.cpc.org br/pdf/CPC_14.pdf>. Acesso em: 20 nov. 2010. CRUZ, Cássia Vanessa Olak Alves; LIMA, Gerlando Augusto Sampaio Franco de. Reputação corporativa e nível de disclosure das empresas de capital aberto no Brasil. Revista Universo Contábil, v. 6, n. 1, p. 85-101, jan./mar. 2010.

CVM. Comissão de Valores Mobiliários. OFÍCIOCIRCULAR/CVM/SNC/SEP/No 03/2009. 2009.

Disponível em: < http://www.cvm.gov.br/port/infos/ Oficio\%20Circular\%20SNC\%20SEP\%2003_2009.pdf> Acesso em: 20 nov. 2010.

DARÓS, Leandro; BORBA, José Alonso. Evidenciação de instrumentos financeiros derivativos nas demonstrações contábeis: Uma análise das empresas brasileiras. Revista Contabilidade \& Finanças, n. 39, p. 68-80, set./dez. 2005. FÁVERO, Luiz Paulo; BELFIORE, Patrícia; SILVA, Fabiana Lopes da; CHAN, Betty Lilian . Análise de dados: modelagem multivariada para a tomada de decisões. Rio de Janeiro: Campus, 2009.

FIGUEIREDO, Gabriela; FAMÁ, Rubens; SILVEIRA, Alexandre di Miceli da. Nível de Endividamento e Transparência das Empresas Brasileiras. In:

SEMINÁRIOS EM ADMINISTRAÇÃO, 8., São Paulo,
Anais... São Paulo: SEMEAD, 2005.

FIPECAFI. Manual de Contabilidade Societária: aplicável a todas as empresas de acordo com as normas internacionais e do CPC. São Paulo: Atlas, 2010.

GALLON, Alessandra Vasconcelos; BEUREN, Ilse Maria; HEIN, Nelson. Análise da relação entre evidenciação nos relatórios da administração e o nível de governança das empresas na Bovespa. Revista de Informação Contábil RIC, v. 1, n. 2, p. 18-41, out./dez., 2007.

HENDRIKSEN, Eldon S.; BREDA, Michael F. Van. Tradução de Antônio Zoratto Sanvicente. Teoria da Contabilidade. 5. ed. São Paulo: Atlas, 1999.

IUDÍCIBUS, Sérgio de. Teoria da Contabilidade. 7. ed. São Paulo: Atlas, 2004.

LANZANA, Ana. Relação entre o disclosure e governança corporativa das empresas brasileiras. 2004. $165 \mathrm{f}$.

Dissertação (Mestrado em Administração) - Faculdade de Economia, Administração e Contabilidade,

Universidade de São Paulo, São Paulo, 2004.

LIMA, Gerlando Augusto Sampaio Franco de. Utilização da teoria da divulgação para avaliação da relação do nível de disclosure com o custo da dívida das empresas brasileiras. 2007. 118f. Tese (Doutorado em Ciências Contábeis) Faculdade de Economia, Administração e Contabilidade, Universidade de São Paulo, São Paulo, 2007.

LIMA, Vinícius Simmer de; LIMA, Gerlando Augusto Sampaio Franco de; LIMA, Iran Siqueira; CARVALHO, Luiz Nelson Guedes de. Determinantes da convergência aos padrões internacionais de contabilidade no Brasil. In: ENCONTRO DA ASSOCIAÇÃO NACIONAL DO PROGRAMAS DE PÓS GRADUAÇÃO EM CIÊNCIAS CONTÁBEIS, 4., 2010, São Paulo. Anais... São Paulo: Anpcont, 2010. CD-ROM.

LOPES, Alexsandro Broedel; MARTINS, Eliseu. Teoria da Contabilidade: uma nova abordagem, São Paulo: Atlas 2005. MALACRIDA, Mara Jane Contrera; YAMAMOTO, Marina Mitiyo. Governança corporativa: nível de 
evidenciação das informações e sua relação com a volatilidade das ações do Ibovespa. Revista Contabilidade \& Finanças. Edição Comemorativa, p. 65-79, set. 2006. MOREIRA, Carolina; NYAMA, Jorge; SANTANA, Cláudio. Avaliação do nível de evidenciação contábil de operações com derivativos: uma comparação entre as informações enviadas à CVM e à SEC pelas companhias abertas brasileiras emissoras de ADR. In: CONGRESSO USP DE CONTABILIDADE E CONTROLADORIA, 6., 2006, São Paulo. Anais... São Paulo: USP, 2006. CD-ROM. MURCIA, Fernando Dal-Ri. Fatores determinantes do nível de disclosure voluntário de companhias abertas no Brasil. 2009. 182f. Tese (Doutorado em Ciências Contábeis) Faculdade de Economia, Administração e Contabilidade, Universidade de São Paulo, São Paulo, 2009.

MURCIA, Fernando Dal-Ri; SANTOS, Ariovaldo dos. Fatores determinantes do nível de disclosure voluntário das companhias abertas no Brasil. Revista de Educação e Pesquisa em Contabilidade, v. 3, n. 2, p. 72-95, mai./ago. 2009.

Teoria do disclosure discricionário: evidências do mercado brasileiro no período 2006-2008. In: ENCONTRO DA ASSOCIAÇÃO NACIONAL DO PROGRAMAS DE PÓS GRADUAÇÃO EM CIÊNCIAS CONTÁBEIS, 4., 2010, São Paulo. Anais... São Paulo: Anpcont, 2010. CD-ROM.

PEREIRA, Dimmitre Morant Vieira Gonçalves; LOPES, Jorge Expedito de Gusmão; PEDERNEIRAS, Marcleide Maria Macedo; SANTOS, Ruthberg dos. Um estudo sobre a relação entre o lucro contábil e o disclosure das companhias abertas do setor de materiais básicos: evidências empíricas no mercado brasileiro de capitais.
In: ENCONTRO DA ASSOCIAÇÃO NACIONAL DO PROGRAMAS DE PÓS GRADUAÇÃO EM CIÊNCIAS CONTÁBEIS, 2., 2008, Salvador. Anais... São Paulo: Anpcont, 2008. CD-ROM.

PERLINGEIRO, Bruna de Carvalho L. Teoria das Escolhas Contábeis: fair value de derivativos em bancos no Brasil. 2009. 196f. Dissertação (Mestrado em Ciências Contábeis) - Faculdade de Economia, Administração e Contabilidade, Universidade de São Paulo, São Paulo, 2009.

TONETTO FILHO, Vitório; FREGONESI, Mariana Simões Ferraz do Amaral. Análise da variação nos índices de endividamento e liquidez e do nível de divulgação das empresas do setor de alimentos processados com a adoção das normas internacionais. In: CONGRESSO USP DE CONTABILIDADE E CONTROLADORIA, 10., 2010, São Paulo. Anais... São Paulo: USP, 2010. CD-ROM.

TORRES, Fernando. Blitz nos balanços. Valor Econômico. 22 fev. 2011.

VERRECCHIA, Robert E. Essays on disclosure. Journal of Accounting and Economics, n. 32, p. 97-180, 2001. YAMAMOTO, Marina Mitiyo; SALOTTI, Bruno Meirelles. Informação contábil: estudos sobre a sua divulgação no mercado de capitais. São Paulo: Atlas, 2006. ZANI, Thobias Bassotto; ZANINI, Francisco Antônio Mesquita; ZANI, João. Governança corporativa e conflito de agência: estudo de caso sobre a utilização de derivativos cambiais por cinco grandes empresas brasileiras. In: ENCONTRO DA ASSOCIAÇÃO NACIONAL DE PÓS-GRADUAÇÃO E PESQUISA EM ADMINISTRAÇÃO, 34., 2010, Rio de Janeiro. Anais... Rio de Janeiro: Anpad, 2010. CD-ROM. 